\title{
A Test Apparatus for the Study of Forced Air-Mixing Devices
}

\author{
T. K. Faison, J. C. Davis, and P. R. Achenbach
}

(October 28, 1965)

\begin{abstract}
The National Bureau of Standards has initiated a study of mixing devices for air streams to improve the techniques for measuring the capacity of air-conditioning, heating, and refrigeration equipment. Better mixers in these test apparatus will reduce the amount of instrumentation required, and increase the accuracy in capacity determinations that are based on enthalpy change of the air passing through the equipment. An apparatus for measuring the effectiveness of mixing devices, a smallscale apparatus for visually observing the mixing process, and some illustrative results are presented. The apparatus for measuring mixer effectiveness generates a stream of moving air of known and reproducible nonuniformity of temperature or humidity, provides for the installation of one or more mixers in a measuring section, and incorporates the means for measuring static pressure, velocity pressure, temperature, and humidity upstream and downstream of the mixer. The flow-visualization apparatus provides a qualitative visual evaluation of the effectiveness of small-scale models of mixers as a basis for selecting the specimens for the more elaborate measurements. Graphic material is included which illustrates the performance of the apparatus and the methods used in determining effectiveness of mixing devices.
\end{abstract}

Key Words: Air-conditioning capacity, air-mixing devices, forced air-mixing, turbulence, mixer effectiveness, apparatus design, air properties, temperature measurement.

\section{Introduction}

Professional societies, standards organizations, and manufacturers' associations have published test procedures for measuring the capacity of heating, airconditioning, and refrigerating equipment in which air is the heat-transfer medium. These standards describe methods for measuring the mass flow rate of air and the unit change in enthalpy of the air stream between selected stations in the air circuit as a means of determining a heating or cooling capacity. Various types of flowmeters have been used for measurement of the mass flow rate of air, and the performance characteristics of some of these have been described in detail in the literature [1]. ${ }^{1}$ The unit change in enthalpy of a stream of air while passing through a heating or air-conditioning device is usually determined from the dry-bulb temperature only when no change in moisture content of the air has occurred, and from the dry-bulb temperature and wet-bulb temperature or dew point if evaporation or condensation has occurred.

In a typical situation the stream of air entering and leaving a piece of air-conditioning equipment is nonuniform with respect to velocity, dry-bulb temperature, and moisture content in the cross section of both the inlet and outlet openings. Under these conditions the enthalpy of the air stream at the inlet and outlet can be accurately determined only if an accurate average of temperature and moisture content of the air is obtained at each station. If the velocity of the air is uniform at the cross section where the temperature and humidity measurements are made, an arithmetic average of these properties in a suitable number of incremental areas of equal size in the cross section is

${ }^{1}$ Figures in brackets indicate the literature references at the end of this paper. adequate. However, if the velocity, temperature, and humidity are all nonuniform, appropriate averages of the temperarue and humidity are very difficult to obtain. On the other hand, if the temperature and humidity of the air stream were made uniform at the measurement stations by a suitable mixing process, the velocity pattern at the measurement stations would not be important, and single measurements of temperature and humidity at each station in conjunction with a measurement of mass flow rate would suffice for determining a net change of enthalpy for the entire air stream.

The simplicity of this latter method is attractive, and from time to time has provided the incentive for limited studies of effective means for mixing an air stream to produce uniform temperature and humidity. Various laboratories have experimented with baffles, louvers, and orifices to meet their own needs for air mixing in a specific test apparatus, and the use of such elements is specified in some standard test procedures $[2,3]$. Turbulence is one of the main vehicles for the transfer of energy from one segment of a stream to another, and the creation of turbulence is an essential part of the mixing process. The current approach to the study of turbulence is statistical, and is usually carried out experimentally by the use of hot-wire anemometer techniques. The literature describes no comprehensive study of flow processes or turbulence that is directly related to the forced mixing of air streams, and no information has been found comparing the effectiveness of various methods or devices for the mixing of nonhomogeneous air streams in the present context.

The National Bureau of Standards has initiated a study of mixing processes and mixing devices for air streams to improve the measurement techniques in the field of air-conditioning, heating, and refrigeration. 
This paper is concerned primarily with the design and function of the apparatus constructed for the investigation. The design features of the apparatus are discussed, a description of a scale-model device used in conjunction with the apparatus is given, and an example of some of the results is presented.

\section{Design Concept}

For experimental evaluation of mixing devices and study of the mixing processes, it was necessary to design an apparatus which could reproduce and control desired conditions in a moving air stream. The criteria for the design of the apparatus were:

(1) To obtain, control, and reproduce the desired velocity and nonuniformity of temperature or humidity conditions in the air stream at a point upstream from the mixer ünder test.

(2) To provide a section for the installation and support of the mixing devices.

(3) To make accurate measurements of the properties of the air stream at selected positions throughout the system.

\subsection{Range of Variables}

The apparatus was designed to produce and maintain control of the several variables in the following ranges:

a. Average air velocity, 0 to $2000 \mathrm{ft} / \mathrm{min}$.

b. Nonuniformity of temperature at the inlet to the mixer, 0 to $20^{\circ} \mathrm{F}$.

c. Nonuniformity of relative humidity at the inlet to the mixer, 0 to 50 percent.

d. Installation of one mixer, or two mixers in series, in the mixer section of the apparatus.

e. Three different temperature or humidity patterns at the inlet to the mixer.

The three variations in temperature pattern that can be produced with the present apparatus are illustrated in figure 1. Other patterns of nonuniform temperature or humidity, such as concentric areas at different conditions, could be investigated by modifying the design of the baffles in the preconditioning section of the duct.

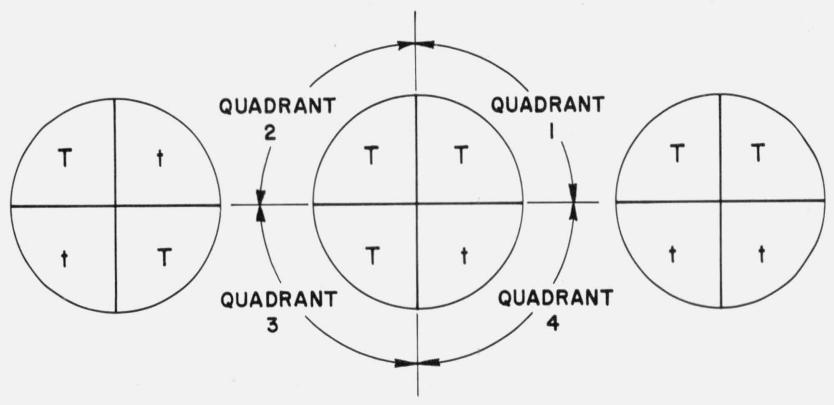

FIGURE 1. Three possible variations of temperature patterns in the test apparatus.

$T$ and $t$, represent quadrants at different temperatures.

\section{Description of Apparatus}

A photographic view and a schematic diagram of the mixing apparatus are shown in figures 2 and 3 , respectively. The entire apparatus performed three main functions, as follows:

(1) Preconditioning the air.

(2) Mixing the air stream.

(3) Measurement of air-stream properties at selected stations.

\subsection{Preconditioning the Air}

The part of the apparatus used for preconditioning the air upstream of the mixer was comprised of an inlet duct and blower and a section of 24 - by 24 -in. duct containing one elbow, and the necessary heaters, humidity sources, baffles, and dividers to establish a known and reproducible variation in temperature or humidity. To control and maintain the nonuniformity in airstream properties, the duct was divided into four quadrants of equal size and shape by internal metal partitions, as shown in section A-A of figure 3. A base electric heater of $5-\mathrm{kW}$ capacity and a trimmer electric heater of $500-\mathrm{W}$ capacity were installed in each quadrant for temperature conditioning. A constant-voltage transformer was used in the supply line to the base heaters to correct for fluctuations in line voltage, and a variable transformer was used on each base heater to select a constant level of energy output. The $500-\mathrm{W}$ trimmer heaters were thermostatically controlled in response to a thermocouple sensing element near section A-A in the test duct. For the trimmer heaters and thermocouple control to be effective in minimizing the time variation in temperature at the measuring stations, it was necessary to limit the temperature differential of the air at the inlet blower to $\pm 0.25^{\circ} \mathrm{F}$.

Water-vapor inlets for humidity variation and control were also located in the conditioning section of the apparatus at section A-A of figure 3. These inlets were arranged so equal or different amounts of water vapor could be supplied to each of the four quadrants of the duct.

The air-flow rate through the test duct was regulated by dampers at the inlet and outlet of the apparatus. By the use of the two dampers it was always possible to maintain a positive pressure in the apparatus, thus preventing leakage of unconditioned air into the system. Additional dampers were used at the entrances of the four quadrants to provide approximately equal volumetric air-flow rates in each quadrant. Mixing baffles were installed in each quadrant of the duct immediately downstream of the elbow, to promote uniformity of temperature and humidity in each quadrant. To avoid as far as practicable premature mixing of the four streams of air before they enter the mixer under test, straightening tubes were placed in the final 18 in. of each quadrant, as shown in section B-B of figure 3. These tubes served to aline the flow as it approached the first measuring station near the outlet of the preconditioning section. 


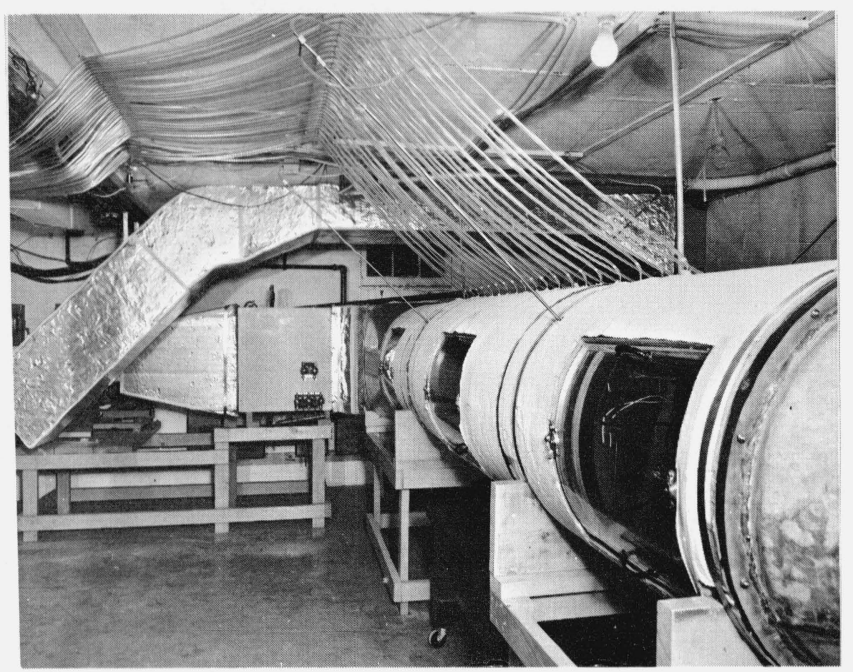

Figure 2. Physical makeup and assembly of test apparatus.

\subsection{Mixing Section}

A conversion piece at the discharge end of the preconditioning section changed the cross section of the test duct from square to circular. A circular duct, 24 in. in diameter, was used for housing the mixing devices. The length of the mixing section could be extended to $9 \frac{1 / 2}{\mathrm{ft}}$ by inserting sections of duct, thus making it possible to study the mixing process for a greater distance downstream from the mixer. The design of the mixing section permitted the installation of two mixing elements in series, and for variation of the distance between them. The mixing section also housed the measuring stations for determing the psychrometric conditions of the air, and the instrumentation for determining the static pressure and velocity pressure of the air upstream and downstream from the mixing device under test. Three removable plastic windows in the side of the mixing section provided access to and observation of the temperature- and pressure-measuring devices and the mixers during the course of the tests.

The mixing section was insulated with formed glassfiber insulation, $1 \mathrm{in}$. in thickness, to reduce the heat transfer in this section and to provide a better environment for temperature and humidity measurement.

\subsection{Measurements and Instrumentation}

Two temperature-measuring stations, each consisting of 24 copper-constantan thermocouples, were used in obtaining temperature profiles upstream and downstream from the mixing device. At each station two thermocouples were located in each of 12 approximately equal areas of the cross section of the duct, as shown in figure 3 at section C-C. For determination of humidity during future studies, 12 of the 24 thermocouples will be converted into wet-bulb thermocouple psychrometers. The thermocouples were made of

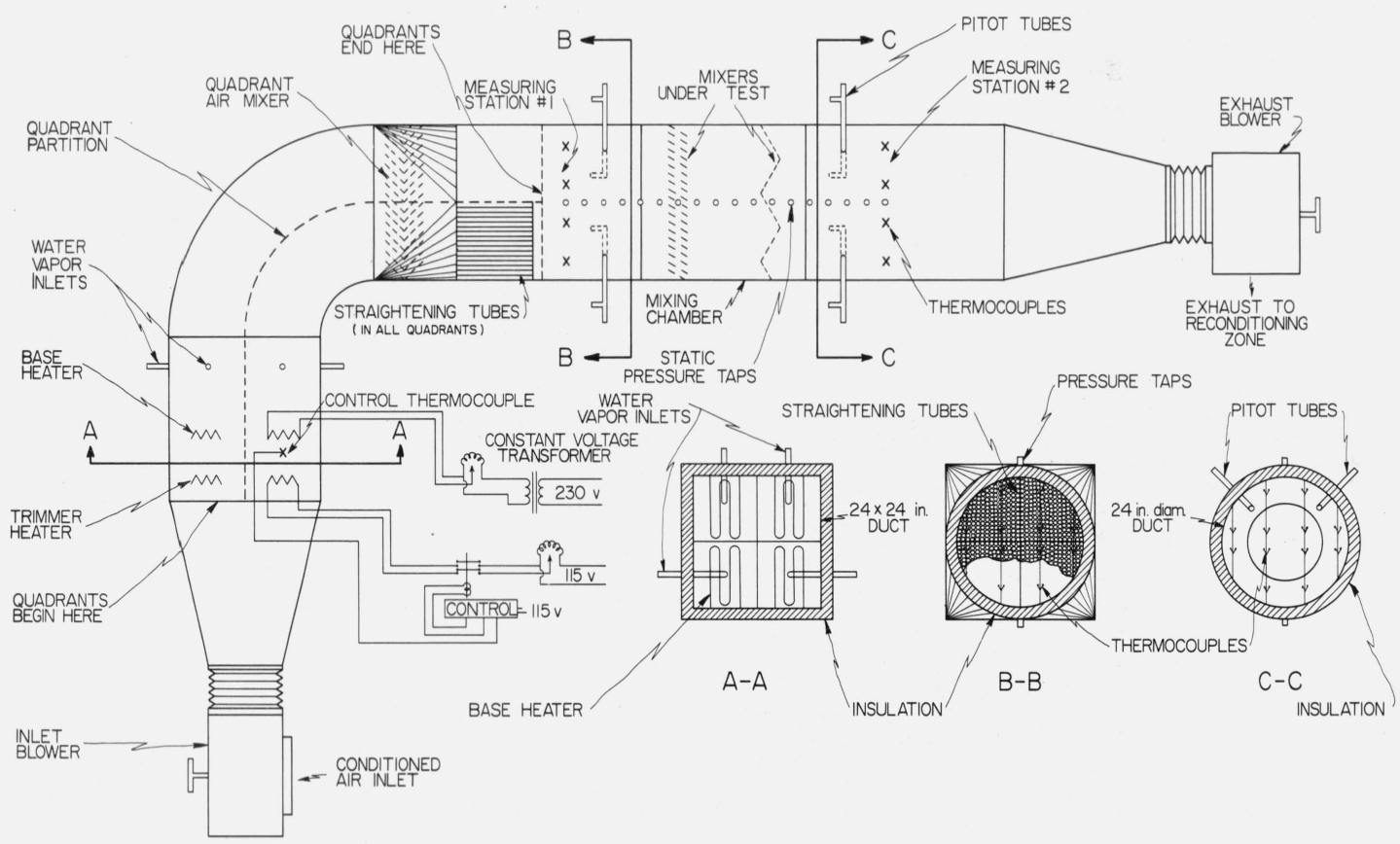

Figure 3. Schematic of apparatus and details showing cross-sectional views. 
30-gage wire calibrated at the National Bureau of Standards. The measuring station located upstream from the mixing device was permanently fixed, and the measurements at this station were made to determine and monitor the degree of nonuniformity in the air stream before mixing occurred. At the downstream measuring station, the nonuniformity of the temperature was measured after passage through the mixer. Since the mixing process for all devices was not the same and the distance for mixing to be accomplished varied with the mixing device, the downstream station was movable so the overall distance required for optimum mixing could be determined.

Each thermocouple was held in a semirigid position by a clamp and a plastic jacket to minimize coldworking of the wire and consequent drift from the original calibration. The lead-lengths of the thermocouples inside the duct were long enough to make conduction errors negligible. The elbow in the preconditioning duct served to shield the thermocouples from the radiant energy of the electric heaters farther upstream, and permitted a greater length of straight duct downstream from the conditioning section in the laboratory space available.

The emfs produced by the thermocouples were measured with a precision manual potentiometer capable of being read directly to the nearest $0.5 \mu \mathrm{V}$ and estimated to $0.1 \mu \mathrm{V}$. The potentiometer was calibrated before use. A temperature-zone box [4] was constructed to permit the use of a common ice bath and an all-copper switching mechinism for sequentially connecting the various thermocouples into the potentiometer circuit, thus eliminating strays emfs from developing in the selector switch. An aluminum plate, $5 \mathrm{in}$. by $10 \mathrm{in.} \mathrm{by} 3 / 8 \mathrm{in}$., was used in constructing the zone box to provide a mass that would maintain a sufficiently uniform temperature at all junctions secured to it mechanically. This plate was enclosed in a block of polystyrene-foam insulation measuring 9 in. by 14 in. by 4 in.

Two pitot-static tubes were installed on diameters $90^{\circ}$ apart at a location just upstream of the mixer under test for making velocity traverses across the section along lines bisecting the four quadrants. Another pair of pitot-static tubes was similarly installed downstream from the mixer. These stations are indicated

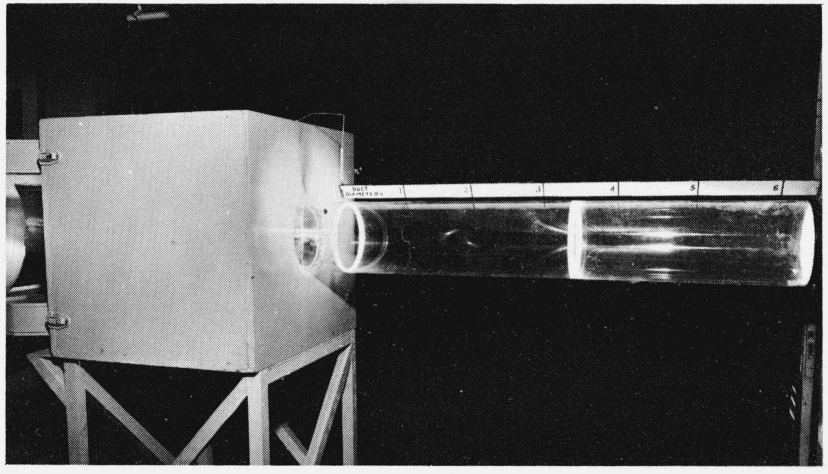

FIGURE 4. Smoke generator and viewing tube used for flow visualization. in figure 3. Static-pressure taps were located at 4-in. intervals along the top of the mixing section between the two temperature-measuring stations to determine static-pressure loss and regain during the mixing process. These pressure taps can be seen in figures 2 and 3 . A Hook gage, readable to 0.002 -in. vertical water column, was used to indicate differential pressure for the measurement of both velocity and staticpressure distribution.

The access doors in the mixing section permitted periodic comparisons between the permanently in stalled thermocouples and other calibrated instruments. Comparisons were made between all of the thermocouples at a given station by immersing all of them in water in a thermos bottle. The difference in emf observed between any two thermocouples did not exceed $0.6 \mu \mathrm{V}$ at either station.

\section{Flow Visualization}

In the study of new devices for mixing air, a technique employing flow visualization and small-scale models was used for a preliminary evaluation of the devices. Smoke [5], titanium tetrachloride $\left(\mathrm{TiCl}_{4}\right)$, was used to simalate the portion of an air stream that was at a different level of temperature or humidity from other portions of the stream. By observing the smoke patterns in the air stream before, during, and after it passed through a mixing device in a section of transparent-plastic duct, the effectiveness of a mixer could be estimated. As new devices were designed and built, observation of the smoke patterns gave a quick visual indication of the quality of the mixing process. Flow visualization was used as a tool for selecting the devices which appeared to warrant more intensive investigation in the larger instrumented apparatus.

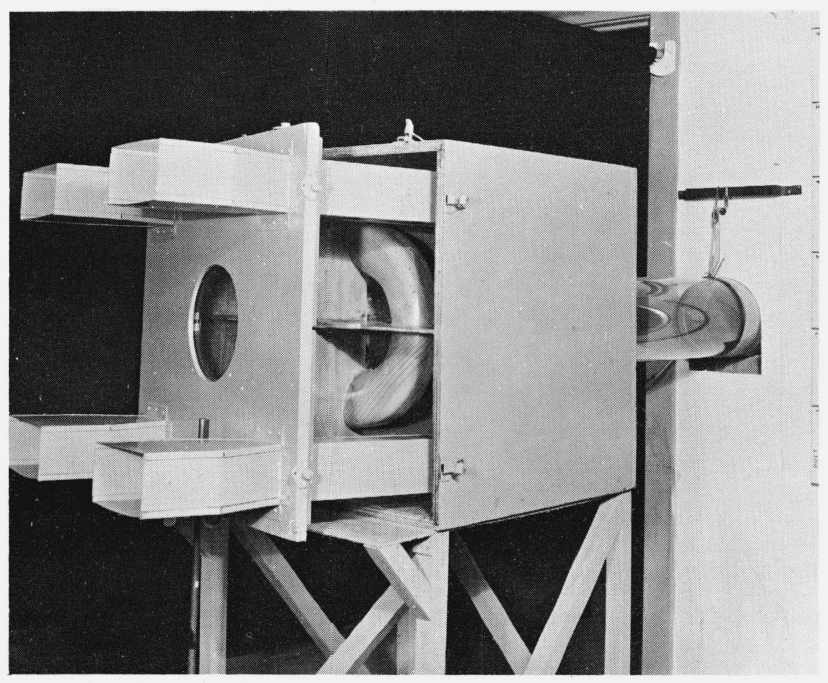

FIGURE 5. View showing internal detail of smoke generator. 
The small-scale mixers used for flow visualization were made geometrically similar to the full-size devices. The Reynolds numbers in the two apparatus also were made approximately equal, in order to make the comparison more indicative. Figures 4 and 5 show the small-scale apparatus used in the flowvisualization tests.

\section{Illustrative Results}

Exploratory tests were performed without a mixing device in the air stream to determine the amount of mixing inherent in the nature of the flow. The results of these tests showed that this was very small, as illustrated in figures 6 and 7 . Figure 6 shows the temperature pattern at the upstream measuring station, which had a temperature difference between quadrants of about $3{ }^{\circ} \mathrm{F}$, and the resulting pattern at the downstream station. The distance between the stations was three duct diameters. Shown in the figure are temperature values in degrees $\mathrm{F}$ at the thermocouple locations in the cross section of the air stream. Also shown is a contour line that represents the $81.0^{\circ} \mathrm{F}$ isotherm and defines the boundary between the three warmer quadrants and the remaining cooler quadrant. The figure also shows that little deformation of the 81.0 ${ }^{\circ} \mathrm{F}$ isotherm had occurred between the two measuring stations.

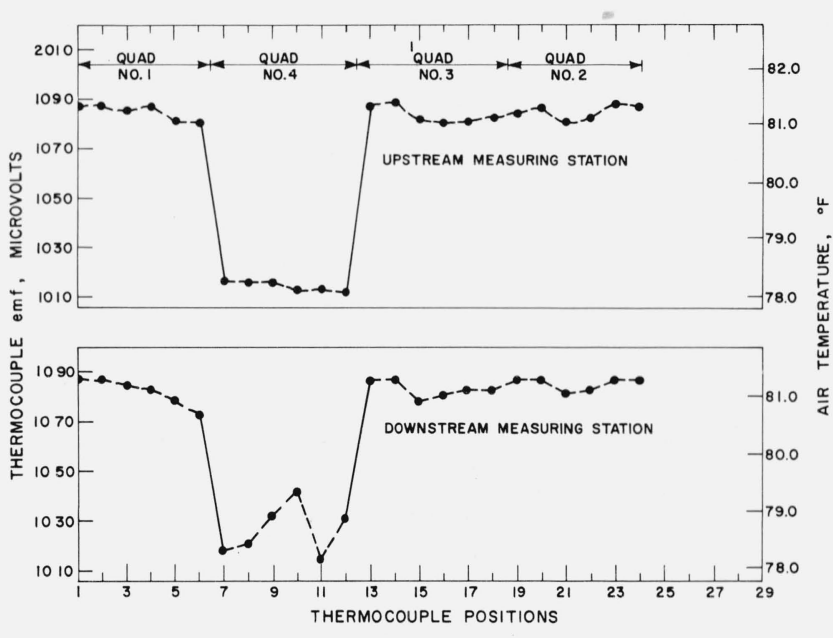

Figure 7. Temperature profiles at upstream and downstream measuring stations without a mixing device in the air stream.

Figure 7 is another illustration of the temperature profile at the two stations for the same test. Corresponding areas at the upstream and the downstream stations are represented by thermocouple positions 1 through 24, respectively. This illustration again shows that inherent mixing between the two stations was small.
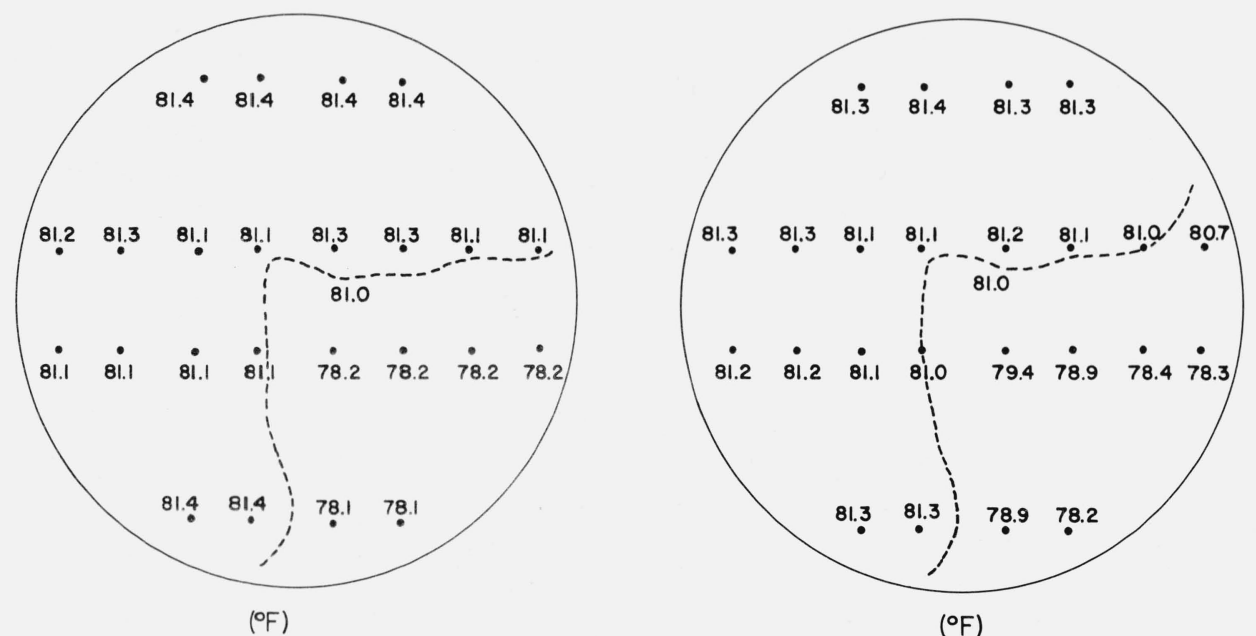

$\left({ }^{\circ} \mathrm{F}\right)$

FIGURE 6. Temperature patterns at upstream and downstream stations without a mixing device in the air stream. 

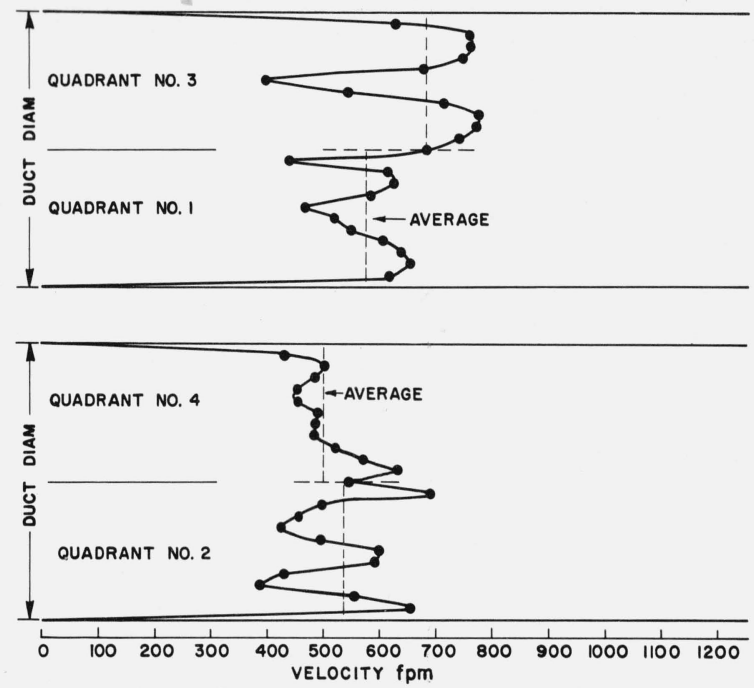

FIGURE 8. Velocity profile at the upstream measuring station.

Figure 8 shows the velocity profile at the upstream measuring station. Measurements were made to show the uniformity of flow at the plane prior to entering the mixing section. The two velocity profiles shown in figure 8 were obtained by setting the two pitot-static tubes in sequence at various radial positions on lines bisecting the quadrants and calculating the velocity for each position using the mean differential pressures given by each tube along with the density of the air. The tubes were alined with the axis of the duct, and it was assumed for the present purpose that the stream was sufficiently alined and its turbulence was sufficiently low to permit neglecting the effects of misalinement and turbulence. The quadrants were not differentially heated for these tests. The inability to get uniformity of velocity and equality of flow in all four quadrants undoubtedly caused some inherent mixing during the test with no mixing device in the air stream. However, the uniformity was sufficient for achieving the desired temperature conditions.

A method was developed for evaluating the effectiveness of different devices or variations in mixer design. The mixing effectiveness was defined as the ratio of the change in the air-temperature variation between the upstream and downstream measuring stations to the temperature variation at the upstream station, expressed as a percent.

\section{Percent effectiveness}

$$
=\frac{\operatorname{Max} \Delta T \text { upstream }- \text { Max } \Delta T \text { downstream }}{\operatorname{Max} \Delta T \text { upstream }} \times 100 .
$$

Figure 9 illustrates the results obtained on a pair of metal-louvered mixing elements spaced 22 in. apart, and the method for determining mixing effectiveness. In this illustration, as in figure 7, the air in quadrants one, two, and three of the test duct was heated about $3{ }^{\circ} \mathrm{F}$ warmer than that in the fourth quadrant. The

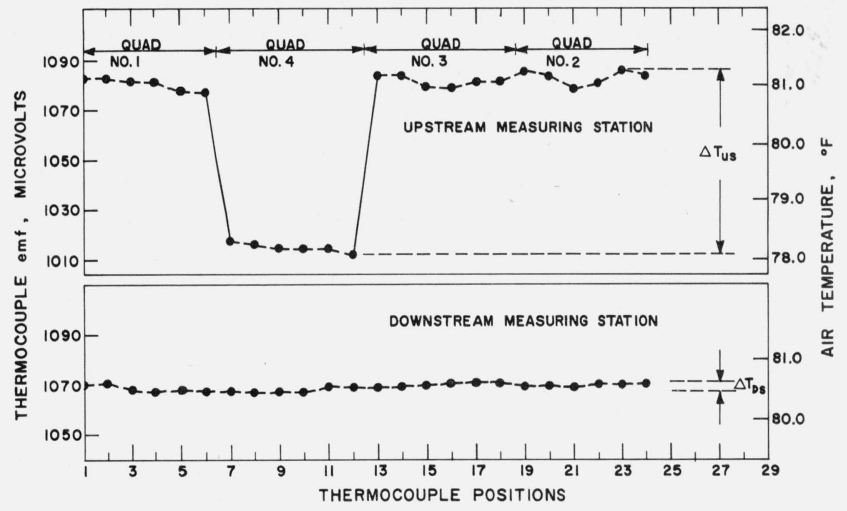

FIGURE 9. Graphs illustrating mixer effectiveness and showing the temperature profiles before and after mixing.

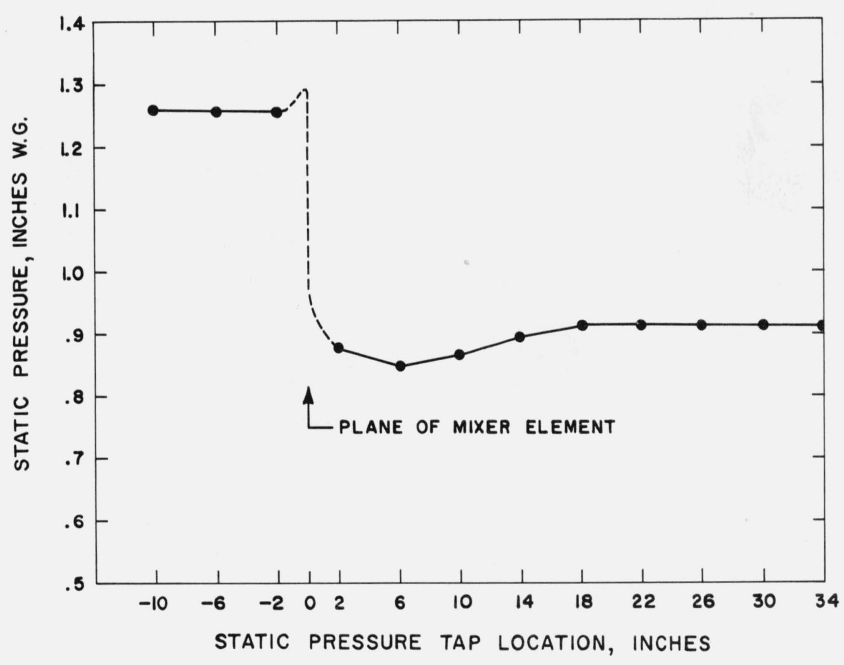

FiguRE 10. Static pressure profile of a louvered type mixer.

observed temperatures at thermocouple positions upstream of the mixers and those at corresponding points 38 in. downstream of the second element are plotted in figure 9. The maximum variation in emf generated by the 24 upstream thermocouples was about $74 \mu \mathrm{V}$, whereas the maximum variation downstream was about $4 \mu \mathrm{V}$, corresponding to an effectiveness of 94.6 percent.

A test at a given set of conditions was comprised of steady-state operation for $1 \mathrm{hr}$ with all thermocouples being read and recorded at 15-min intervals. The conditions were considered to be steady when the variation in emf produced by each thermocouple was $6 \mu \mathrm{V}$ or less during the 1-hr period.

Figure 10 shows a static-pressure profile along the top of the duct from a point $10 \mathrm{in}$. upstream of a mixing device to a point 34 in. downstream of the device in increments of $4 \mathrm{in}$. The static pressure is actually the pressure relative to that of the room in which the equipment was located. This illustrates the sharp pressure drop at the plane of the mixer accompanied by a small regain of static pressure which reached a 
maximum about 18 in. downstream of the mixer. Tests of several mixers have indicated that mixing is approximately complete at the plane where maximum static-pressure regain was first observed. Thus, the pressure profile offers a simple method for determining the approximate location of final mixer effectiveness.

Tentative plans for future study of mixing devices will include investigation of the following parameters of design and application.

(a) Magnitude and pattern of upstream temperature and humidity variation.

(b) Use of more than one mixer in series.

(c) Relation of mixing effectiveness to the distance between elements and the distance to the plane of downstream measurement.

(d) Variation of air velocity.

(e) Effectiveness of orifices, baffles, turning vanes, screens, and other configurations as mixers.

In addition to the items mentioned above, a hotwire anemometer will be used to investigate the turbulence and determine, for example, the intensity and integral scale of the turbulence and its energy spectrum. An attempt will be made to correlate such quantities with the mixing effectiveness determined from temperature, humidity, and velocity measurements.

Since one immediate use of air-mixing devices is their application to apparatus for measuring capacity of heating or cooling equipment, the usefulness of a given design will be related to its mixing effectiveness, the space required to attain maximum mixing, and the static pressure loss through the device. As various devices are investigated, a function or figure of merit will be sought for comparing the overall usefulness of different designs. The information furnished through the study should provide for better and easier measurement of stream conditions in moving air. Effective mixing of air streams will have application in fields other than air conditioning, such as the sampling of flue gases for analysis, air filter testing, fluid mechanics investigations, and other processes where homogeneity would improve accuracy of measurement or be desired for other reasons.

\section{References}

[1] Fluid meters: their theory and application, 5th ed., Am. Soc. Mech. Eng. (1959).

[2] Methods of testing for rating unitary heat pump equipment, ASHRAE Standard 39.61, Am. Soc. Htg. Refr. and Air-Cond. Eng. (1961)

[3] Institute of Boiler and Radiator Manufacturers Testing and Rating Code for Low Pressure Cast Iron Heating Boilers, 7th ed. (1964).

[4] Temperature: Its Measurement and Control, Thermoelectric Thermometry 1, 202 (Reinhold Publ. Co., 1941).

[5] R. L. Maltby and R. F. A. Keating, Flow visualization in low speed wind tunnels, Current Brit. Practice Tech. Note AERO 2715, Royal Aircraft Establishment (Aug. 1960).

(Paper 70C1-169) 